\title{
DESIGNING, DEVELOPING AND EVALUATING A SUSTAINABLE SHARIAH-COMPLIANT E-COMMERCE FASHION PROTOTYPE
}

\author{
Naginder Kaur \\ Academy of Language Studies, Universiti Teknologi MARA Perlis Branch
}

Nadia Abdul Wahab*

Faculty of Computer \& Mathematical Sciences, Universiti Teknologi MARA Perlis Branch

Syafiqa Amira Zulkifli

Faculty of Computer \& Mathematical Sciences, Universiti Teknologi MARA Perlis Branch

\begin{abstract}
This paper describes the full process of design, development and evaluation of a Shariah-compliant ecommerce fashion prototype. The prototype was designed and developed based on Fogg's (2003) Persuasive Technology principles, namely, the principle of suggestion, principle of similarity and principle of trustworthiness which are able to persuade consumers to visit and eventually purchase products from this site. User Experience Testing was conducted to evaluate user experience in terms of screen layout, features and functionality of the site. Findings of the study indicate that the information offered is useful and the website is well-designed. In addition, the suggestions on size and clothes based on users' body measurement are helpful when choosing suitable clothes based on one's body type. Therefore, it can be concluded that Shariah-compliant fashion on this e-commerce site is interesting, useful and user friendly, and thus, can be a sustainable go-to site of e-commerce for Muslim women.
\end{abstract}

Keywords: Shariah-compliant Fashion, User Experience Testing, Persuasive Technology, E-Commerce, Fashion Prototype

Received: 4 May 2020

Accepted: 31 July 2021

https://doi.org/10.33736/ijbs.4296.2021

\section{INTRODUCTION}

Every Muslim woman is required to wear Shariah-compliant clothes as ordained in the Qur'an and Hadith. Covering aurah (all parts of woman's body except the face and hands) is a command from Allah for all Muslim women in the Holy Qur'an (24:31), based on the principles of Islamic Shariah Law. In addition, Muslim women should also wear clothes that suit their body shape and size, which will enhance their self-esteem and satisfaction (Mustafa@Busu et al., 2018). Unlike

\footnotetext{
- Corresponding author: Faculty of Computer \& Mathematical Sciences, Universiti Teknologi MARA Perlis Branch, 02600 Arau, Perlis, Malaysia; Tel: +6(04) 988 2263; Email: nadiawahab@uitm.edu.my
} 
conventional clothing where women's limbs can be seen, for example when wearing skirts, shortsleeved blouse, on the contrary, Shariah-compliant attire for Muslim women, as prescribed by the Holy Qur'an requires an individual to cover all parts of the body except the face and hands and to avoid wearing clothes which are sheer or tight. Covering aurah symbolises the dignity of Muslim women while also protecting themselves from becoming an attraction for men (Fatema et al., 2013; Mustafa@Busu et al., 2018).

Nowadays, many businesses and firms use e-commerce site to ensure effective and reliable business processing (Kotler \& Keler, 2012; Smith, 2011). E-commerce sites are beneficial for users as they help save time, allow easy access for purchasing through applications which can be used any time of the day regardless of where the company / supplier is located (Omar \& Anas, 2014). One of the advantages of using e-commerce is that companies can expand their market much easily as well as increase their sale revenue (Nemat, 2011). Besides, it can also help companies gain feedback from customers more easily and adapt accordingly, which in turn will increase customer loyalty, company image as well as its brand standing (Khan, 2016). Additionally, in wake of the COVID-19 pandemic and the slowing economic activity, there has been a surge in e-commerce where businesses and consumers are increasingly going digital, providing and purchasing more goods and services online (Tran, 2021), thus overtaking the brick-and-mortar retail, which has largely been put on hold, at least temporarily (OECD, 2020). As the pandemic has compelled people to limit physical interactions and outings o the malls or physical stores owing to confinement and social distancing protocols, e-commerce has gained significant momentum and much prominence in our lives today.

One of the product types that Malaysians have a strong affinity and preference for is Shariahcompliant apparels, which can be classified as modest fashion. With a whopping worldwide revenue of US\$ 283 billion globally in 2018, it is projected to reach US\$ 402 billion in 2024 (Lim, 2020). The Muslim majority makes up $61.3 \%$ of Malaysian population, therefore, Shariahcompliant Muslimah fashion is a niche business, forecasted to grow substantially as consumers are ever willing to spend on fashion products. To affirm this, we can see for example, Zalora, the top fashion e-commerce marketplace saw an average selling rate of around $57.5 \%$ from 2,810 stock-keeping units in 2019 (Lim, 2020).

In view of the rapid growth in e-commerce today, currently in Malaysia there are a few ecommerce fashion app that sells clothes that are Shariah-compliant (for example, Naelofar, PopLook, Sabella, dUCK) as Islamic fashion seems to be on the rise in Malaysia (Salvá, 2017). However, according to a base line preliminary investigation carried out by the researchers on 80 Muslim men and women (79\% females, $21 \%$ males) within the range of 20-50 year-olds, selected randomly in the northern region of Malaysia, it was found that more than half $(53.2 \%)$ of the respondents disagreed on the availability of existing fashion e-commerce app selling fully Shariah compliant clothes. In addition, there is no e-commerce fashion app that is able to recommend or suggest apparels based on the user's physical appearance or body type. If Muslim women continue to make online purchases at any non-Shariah compliant e-commerce fashion site, they may risk their obligation of covering aurah in accordance with Islamic law. Besides, without guidance of the right type of app, they may buy unsuitable clothes that do not match their body shape and size. This will ultimately lead to unsatisfactory purchase and thus, waste time and money in addition to the frustration that comes with it. 
Therefore, it is imperative to further enquire how a Shariah-compliant website would address all the various aspects and concerns as highlighted in previous studies and existing apps. In response to the above situations and scenario, which may or may not affect the general population of all Muslim consumers (due to limited sample size), this study was thus embarked to further develop a Shariah-compliant e-commerce fashion website for Muslim women which allows them to choose Shariah-compliant attire based on personal body shape and size. The research has two broad objectives which are: a) to design an e-commerce prototype that is able to help Muslim women in choosing Shariah-compliant clothes based on their body shape and size, and b) to evaluate users' experience of the e-commerce prototype by utilising the User Experience Test. The website, named AZALEA, is also expected to help increase the sale, revenue, credibility, and marketing strategies for target customers, thus, this study makes significant contribution of helping to increase the number of Shariah-compliant e-commerce fashion sites in Malaysia, which in turn would allow more Muslim women to cover their aurah by wearing Shariahcompliant clothes as required in the Qur'an and Hadith. Besides, the e-commerce fashion also has the capacity of offering viable suggestions based on customers' body shape and size, a feature which is not available in other fashion websites. This study will also contribute to the existing literature in support of Persuasive Technology principles, also known as persuasion power due to its ability in persuading users. The principles used will help the e-commerce fashion site to attract users' attention to visit and purchase fashion items from this site.

\section{LITERATURE REVIEW}

Jan et al. (2015) explain that fashion is able to identify someone's identity and personality. As people's choices change, so does fashion. This implies that fashion is not everlasting as it is dependent on the choices users make. Fashion items for women include apparel, scarves, shoes, cosmetics and accessories. Scarves, also known as hijab are also related with Islamic fashion (Jan et al., 2015). As Shariah and Halal are two integral aspects in developing an Islamic brand (Alserhan, 2010; Jumani \& Siddiqui, 2012; Ozgen \& Kurt, 2013; Temporal, 2011; Wilson \& Liu, 2011) which can provide goods or services to meet the requirements of Muslim consumers, hence, in establishing an Islamic fashion brand, it is invariably necessary to comply with Shariah requirements.

\subsection{Criteria in Choosing Clothes}

Internal and external factors tend to influence users' fashion-related purchasing decisions. The extent of an individual's interest in clothing is largely contingent to his/her beliefs, attitudes, knowledge, attention, and curiosity about clothing (Cham et al., 2017). Apparel attribute is an important criterion in choosing clothes (Cham, et al., 2017), including quality of clothes, type of fabric, brand name, designer's name, style and price. Users' expectations on apparel product are also based on information cues including country of manufacture, price and brand name (Swinker \& Hines, 2006).

Next, demographic variables, namely age and ethnicity (Kotler \& Keller, 2012) are important variables that strongly influence purchasing decisions. The seller can predict the products that users will purchase based on ethnicity background and the environment surrounding its users 
(Tajuddin et al., 2010). Many aspects of user behaviour such as brand loyalty, patterns and advertising perceptions have been influenced by ethnicity.

Lastly, the factor of age can influence users in making purchasing decisions. Younger customers tend to buy low-priced clothes, while older customers' choice is primarily based on suitability of clothes (Hervé \& Mullet, 2009). Besides that, the younger age who is more familiar and adept at technology makes purchasing decisions based on information gathered from technology rather than asking friends or others (Ryu \& Han, 2009) while older consumers select apparels on information sources such as media advertisements and suggestions from others.

\subsection{Other E-commerce Fashion Sites in Malaysia}

There are currently a few fashion e-commerce sites in Malaysia (see Table 1). These applications sell the latest types fashion and provide description of every item of apparel. However, all these e-commerce sites do not offer suggestions based on users' personal body shape and size, while some of these sites are not fully Shariah-compliant as the models do not wear a headscarf/hijab to cover their head and some of the clothes sold are sheer or tight.

Table 1: Comparative Analysis on Existing E-commerce Fashion Sites

\begin{tabular}{|c|c|c|}
\hline $\begin{array}{c}\text { E-commerce } \\
\text { Fashion }\end{array}$ & Technology & Description \\
\hline Zalora & $\begin{array}{l}\text { - Mobile app } \\
\text { - Website }\end{array}$ & $\begin{array}{l}\text { - } \text { Provides a category for Muslim clothes } \\
\text { - Users can search by categories such as hijab, dress } \\
\text { - Provides video and images of apparels from different angles } \\
\text { - Offers a few suggestions on related items } \\
\text { - Users can zoom in to the images } \\
\text { - Unable to suggest suitable clothes according to users' body } \\
\text { - } \text { shape and event to attend } \\
\text { - } \quad \text { Most of the models do not wear hijab }\end{array}$ \\
\hline PopLook & $\begin{array}{l}\text { - Mobile app } \\
\text { - Website }\end{array}$ & $\begin{array}{l}\text { - Focuses on Muslim women apparels } \\
\text { - Users can search by categories such as sportswear, work-wear } \\
\text { - Users can zoom in to the images } \\
\text { - Provides a few suggestions on related items } \\
\text { - Provides images of apparels from different angles } \\
\text { - Does not suggest suitable clothes according to users' physical } \\
\text { - } \text { appearance } \\
\text { - Some of the models do not wear hijab }\end{array}$ \\
\hline FashionValet & - Website & $\begin{array}{l}\text { - Provides a few categories such as beauty and apparels } \\
\text { - Users can zoom in to the images } \\
\text { - Provides a few suggestions on related items } \\
\text { - Offers images of apparels from different angles } \\
\text { - Does not suggest suitable clothes according to users' body } \\
\text { - } \text { shape and event to attend } \\
\text { - Some of the models do not wear hijab }\end{array}$ \\
\hline
\end{tabular}


Even though there are a few e-commerce fashion sites in Malaysia which have developed and use technology widely, there are still some persistent flaws especially in helping users in choosing suitable clothes. The suggestion from e-commerce fashion sites and Shariah-compliant clothes for Muslim women users is important and helpful for e-commerce fashion to survive and thrive. However, the absence of viable suggestion and advice from these sites has motivated the present study to develop an e-commerce fashion site that is able to help users choose clothes.

\section{METHODOLOGY}

This study was carried out in five phases: (i) Awareness of Problem, (ii) Suggestion, (iii) Development, (iv) Evaluation, and (v) Conclusion based on Design Science Research Methodology. This methodology was chosen as it offers specific guidelines for evaluation and iteration within research projects. The study also involves User Experience Testing (UX Testing) with randomly selected sample through a questionnaire and open-ended interviews. The UX Testing was conducted in a public area in Perlis, Malaysia. Descriptive statistics using SPSS were used to analyse the data obtained from the participants. Persuasive Technology was probed as a guideline in designing and developing this Shariah-compliant e-commerce fashion site.

\subsection{Prototype Design}

Persuasive Technology which was created by Fogg (2003) was chosen and applied during the design of the user interface. The principles applied were Principle of Suggestion, Principle of Similarity and Principle of Trustworthiness This activity produced a UI design for the fashion ecommerce fashion site.

According to Fogg (2003), the principle of suggestion is a certain action or behaviour which is the most opportune. Figure 1 shows that the principle of suggestion was applied in this ecommerce site. The researchers developed the Shariah-compliant fashion e-commerce that is able to give suggestions of clothes to users according to body shape and suggestion of size. There are four types of body shapes and each type has different suggestions of clothes. This site also suggests a suitable size for users according to their body measurement.

In this Shariah-compliant e-commerce fashion, the researchers designed the prototype by making it similar to the target audience, that is, Malaysian Muslim women. It conveys similarity through Muslim women models who are of similar race, religion, and gender. This is in line with the principle of similarity that states people or computing technology products which are similar to users in terms of personality, preferences or in other attributes are more easily persuaded than people who are not similar (Fogg, 2003).

Principle of trustworthiness states that a system should provide customers with truthful, fair and unbiased information (Fogg, 2003). To increase persuasion, the Principle of Trustworthiness was applied by providing important information such as stating privacy policy, company information and contact information, including the store address and telephone number for users' reference.

\subsection{Development of Prototype}


This section discusses the development of e-commerce fashion prototype called AZALEA. The development of this site involved the creation video, development of web based Adobe Dreamweaver and database creation and integration using MySQL. A name and symbol such as logo, trademark and package design are necessary for a brand of goods or services and to differentiate these goods or services from those of competitors. For this Shariah-compliant ecommerce fashion, the researchers created a logo using Adobe Photoshop.

Figure 1: Logo of the E-commerce Fashion Site

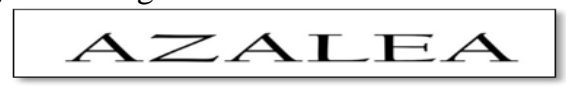

Next, coding was done using Adobe Dreamweaver CS6 to produce user interface of the Shariahcompliant e-commerce fashion. The CSS code was used as a template for this fashion web while php and html codes were used to be displayed at the web browser and processes. Figure 2 shows the screenshot of the video production. This video helps users to measure their body measurement correctly. Wondershare Filmora was used to create the video.

Figure 2: Screenshot of Video Creation

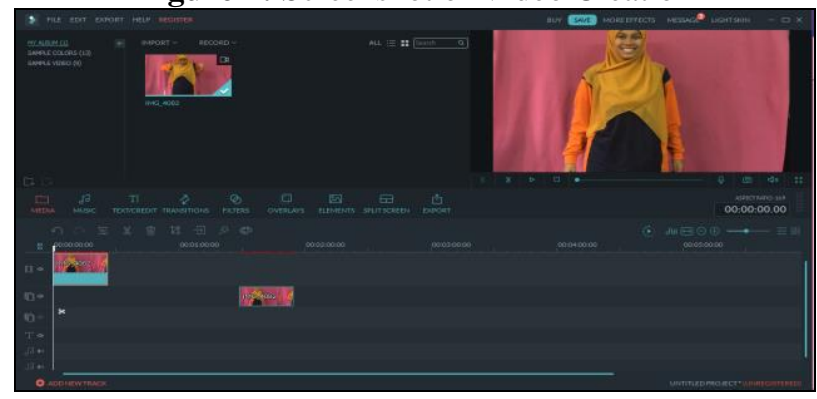

\subsection{Screenshots of Prototype}

Figure 3 shows screenshot of the login interface. This interface is an important part of the system to check the authorised user. An authorised user has to enter his/her email address and password to login. If the email address or password is incorrect, the system will display an error message.

Figure 3: Screenshot of Login Interface 


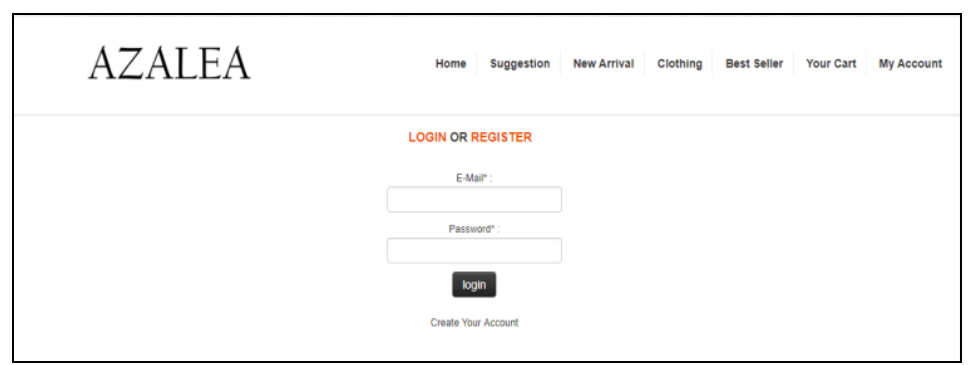

Furthermore, the registration interface as shown in Figure 4 is required for registration of new users. New users have to fill in the form and can click the on video to watch the tutorial on doing body measurement. This video is offered by the site to help users do their body measurement accurately. All data filled in will be saved in the database.

Figure 4: Screenshot of Registration Page

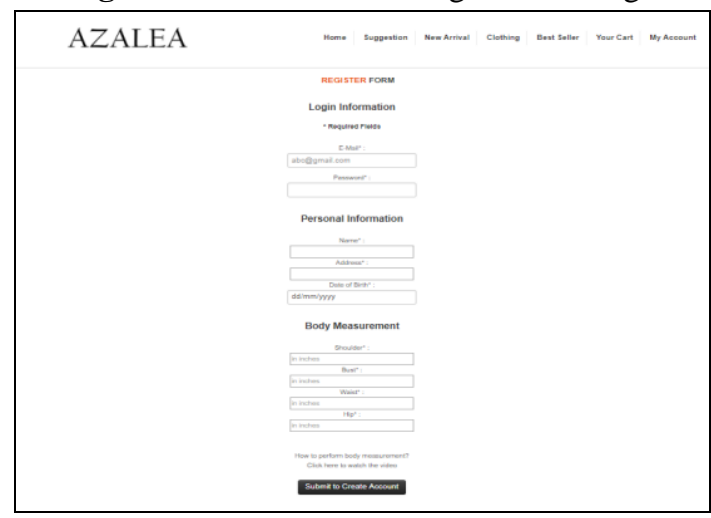

Figure 5 shows the screenshot of suggested clothes and size interface for an authorised user. Non-registered users will not get access to the suggestions on the website. This page also provides a few tips for users which assist users in choosing and purchasing suitable clothes.

Figure 5: Screenshot of Suggested Clothes and Size Interface 


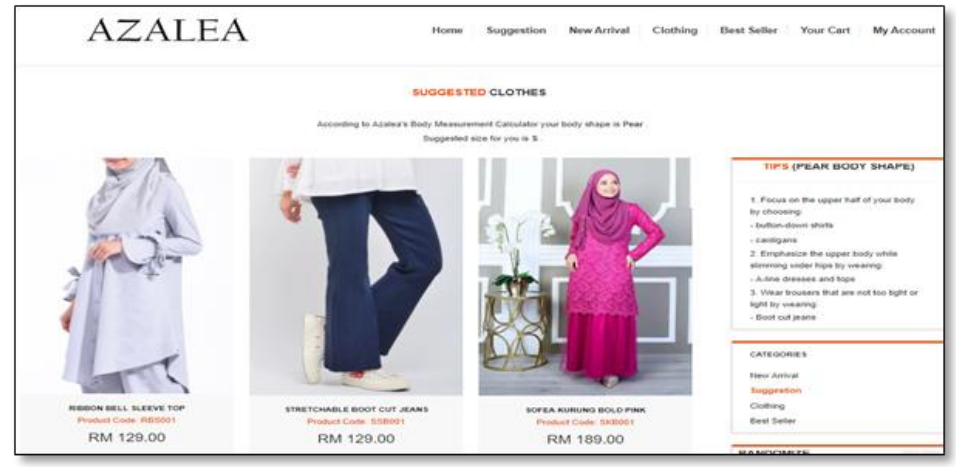

\section{FINDINGS AND EVALUATION OF THE PROTOTYPE}

\subsection{User Experience Testing}

The User Experience Testing (UX Testing) was conducted to evaluate user experience in terms of screen layout, features and functionality of the site. Six and Macefield (2016) suggest that three to 20 participants suffice in providing valid results, and a good baseline is between five and 10 participants. In general, there should be more participants for more complex, highly critical projects; while fewer participants are necessary when testing more novel designs (Six \& Macefield, 2016). In this study, the UX Testing was carried out with 30 respondents (21 females and nine males), randomly drawn from the general population.

These respondents comprised individuals from varying segments, namely students, working adults, young adults as well as male respondents, who were between 18 to 50 years of age. The inclusion of male responses was deemed necessary too in order to obtain male insights, who may have vested interest in the website in making selections and purchases for their mother, wife, daughter, or sister. Athough men are more needs-based shoppers instead of leisure shoppers like women (Chea, 2011), they do tend to spend more money on shopping than women in comparable activities (Bakewell \& Mitchell, 2004, as cited in Chea, 2011, p. 8), and hence, male input and perspectives are of equal value. On the whole, the objective of this test was to assess users' understanding, emotions and expectations of the website (Garrett, 2010). The results of this test were used to improve the Shariah-compliant e-commerce fashion website. During the UX Testing, users were given the opportunity to explore the website, and subsequently respond to a questionnaire and open-ended interview to request for further clarification on their experience of the website.

The questionnaire for UXT consisted of 11 items including respondents' demographic information and eight items related to users' experience and another two open-ended questions were further suggestions of the website. The results from the UX Testing were analysed using descriptive statistics and are presented in a histogram to describe the basic features of the data in this study. Table 2 shows the frequency and percentage of items 1, 2, 3, in the UX Testing while Figure 6 shows the UX Testing results in a bar chart. The statistics reveal that most of the users $(86.67 \%)$ agreed that the information provided in the website is easy to find and clearly 
presented. It was also found that majority of users (90\%) agreed that the information they were seeking is clearly presented. About $80 \%$ of the users agreed that they were able to find what they were looking for in the website. Overall, it can be said that this Shariah-compliant fashion website provides a clear and easy-to-find information to maximise users' satisfaction while shopping at this website.

Table 2: Frequency and Percentage for Item 1-3 of the Questionnaire in the UX Testing

\begin{tabular}{lcccc}
\hline \multicolumn{1}{c}{ Questions } & Yes & Yes (\%) & No & No (\%) \\
\hline Was the information easy to find? & 26 & 86.67 & 4 & 13.33 \\
Was the information clearly presented? & 27 & 90.0 & 3 & 10.0 \\
Were you able to find what you are looking for? & 24 & 80.0 & 6 & 20.0 \\
\hline \hline
\end{tabular}

Figure 6: Results for User Experience Testing

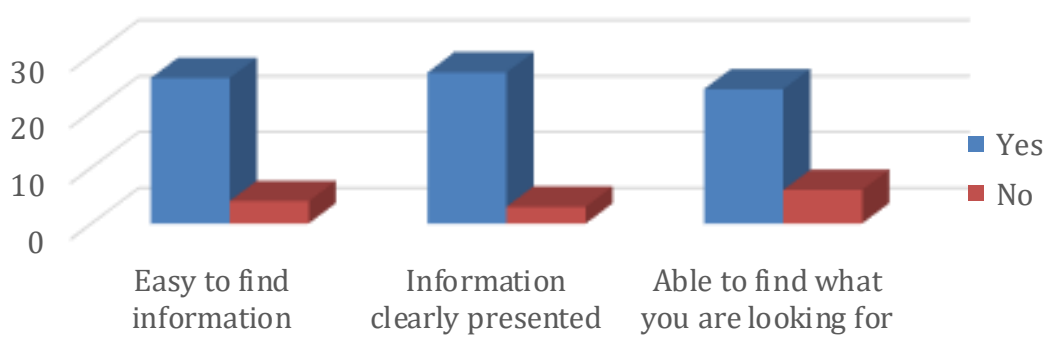

The evaluation range of user preference for item $4-8$ in the UX Testing questionnaire was answered based on the range of 5 (Strongly Agree), 4 (Agree), 3 (Neither Agree nor Disagree), 2 (Disagree), and 1 (Strongly Disagree). Table 3 shows the statistics for items 4 to item 8 from the UX Test questionnaire. The items basically assess users' opinions in terms of the suggestion of product based on body shape and product size, accessibility, content and presentation of website.

Table 3: Descriptive Statistics of the Results

\begin{tabular}{lccc}
\hline \multicolumn{1}{c}{ Items } & Min & Max & Mean \\
\hline The suggestion of products based on your body shape is helpful. & 4 & 5 & 4.67 \\
The suggestion of size in this website is helpful. & 4 & 5 & 4.73 \\
How would you rate our site in terms of accessibility? & 3 & 5 & 4.43 \\
How would you rate our site in terms of content? & 3 & 5 & 4.30 \\
How would you rate our site in terms of presentation? & 4 & 5 & 4.83 \\
\hline \hline
\end{tabular}

Based on Table 3, for item 4 and 5, it was found that the mean score for suggestion of products based on users' body shape is 4.67 while mean score for suggestion of size is 4.73 . Figure 7 depicts this in a bar chart which proves that most users found suggestions of clothes based on body shape and suggestion of size offered by the website to be helpful. In terms of accessibility, the mean score is 4.43. This shows that most users had a good experience accessing the website. The mean score of item 7 and item 8 is 4.3 and 4.83 respectively. This shows that in terms of content and presentation, most users had a good experience in this e-commerce site. 
Figure 7: Mean Score of User Experience Testing

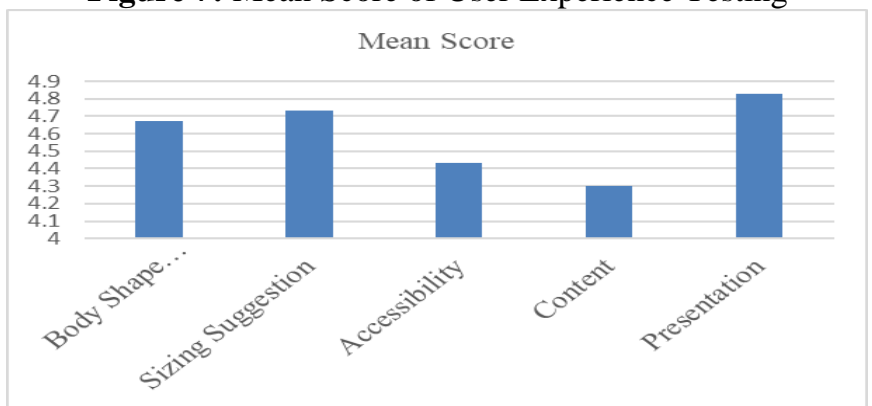

The results User Experience (UX) Testing clearly indicates that the information provided within the prototype is useful and the website is well-designed. In addition, the suggested size and clothes based on users' body measurement is helpful for users to choose suitable clothes based on their body shape. Therefore, it can be concluded that this Shariah-compliant fashion e-commerce is interesting, useful and user friendly and users have good experience using this prototype.

Figure 8 shows the recommendation of email input from the respondents. Email input must be correctly typed. For example, email address without "@" is considered to be invalid email, therefore, error message is sent to the said user. Invalid email will disrupt the registration process, which cannot proceed until the email address is correctly entered.

Figure 8: Recommendation of Email Input

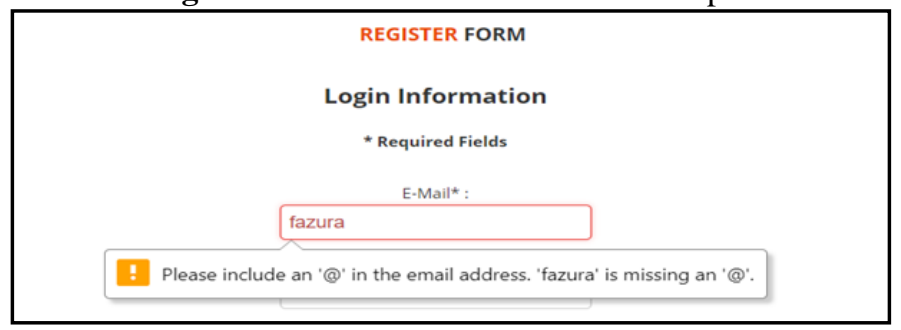

Besides that, the navigation button to return page was also suggested by one of the users who realized that she needed to use previous button in the web browser to go back to the previous page. Figure 9 shows the enhancement for previous navigation button in the video page.

Figure 9: Recommendation of Return Navigation 


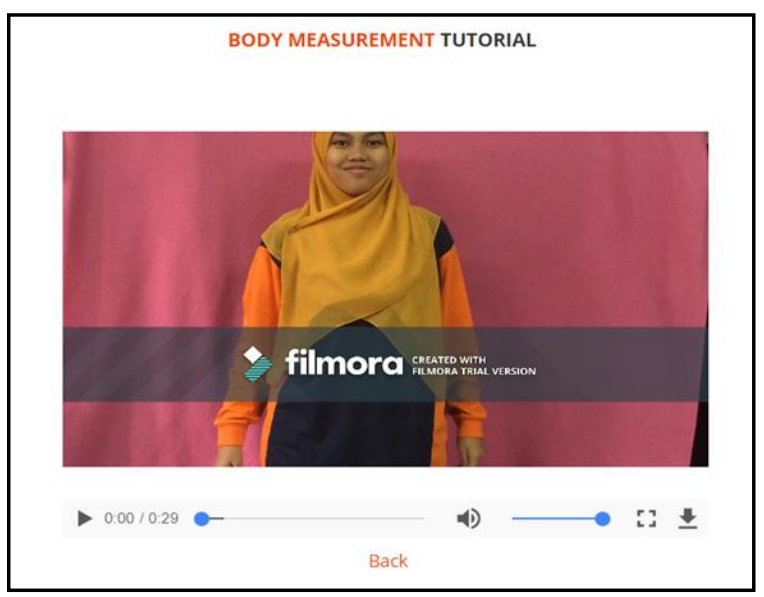

Finally, the add-to-cart process was also found to be crucial as the respondents cited the cart to be one of the most important processes in e-commerce. During the user experience testing, the cart functionality still had an error and could not display the data in the table. This was rectified and the process of add to cart is now able to display the items added and the total price as shown in Figure10.

Figure 10: Cart Function

\begin{tabular}{|c|c|c|c|}
\hline Order Details \\
\hline Item Name & Quantity & Price & Action \\
\hline WRAP KURUNG AMBER GOLO & 1 & RM 149 & Remove \\
\hline SOFEA KURUNG BOLD PINK & 1 & RM 189 & Remove \\
\hline BOOTCUT & 1 & RM 129 & Remove \\
\hline ARDANI BLOUSE & 1 & RM S9 & Remove \\
\hline WRAP KURUNG AMBER GOLD & 1 & RM 149 & Remove \\
\hline
\end{tabular}

\subsection{Qualitative Perceptions and Insights of Participants}

During the UX Testing, an exploratory interview was also conducted with all the 30 participants in order to gain more understanding on how they feel about the e-commerce site and to get suggestions on how to improve the site. The salient findings from the participants are hereby discussed.

It was found that 27 of the 30 participants (90\%) agreed that the suggested size and clothes based on users' body measurement is an interesting feature of this site as it assists the users in deciding on what clothes to choose. During the interview, 11, participants agreed that this feature should be included in other fashion e-commerce sites too as it is able to assist customers in choosing the right clothes for themselves. Among the 11 affirmative responses, seven participants contended that this feature saves them time in making decision during the purchasing process. 
The participants also shared that the structure of AZALEA site is simple and clear without unnecessary complicated aspects. For example, more than $80 \%$ were satisfied with the adoption of simple layout design with basic typography and standard menus and buttons. Among the positive comments made by the participants are:

"This site utilizes basic fonts and the simple layout design."

"I like the minimalistic design of this site and the page load really fast."

"The site is clean and simple, with a basic and navigation bar."

"AZALEA has a professional look, with a simple color scheme and large lettering."

Additionally, the site is straightforward as there is no extraneous and misplaced information. AZALEA uses white space to make it easy for readers to understand exactly what the site is all about within minutes of log-in. This is an important aspect to keep a customer engaged and logged-on as perceived usefulness enhances an online shopper's experience and reinforces their shopper's intention to continue using a website, (Rao et al., 2018). To avoid a sense of clutter and distraction, AZALEA also leaves its site clean. By providing a simplistic header bar with navigation options, this site makes it easy to use for learning about products or buying them. Many positive comments were expressed in support of this, for example:

"The list of products is not cluttered and the information is easy to read and understand."

"This site directs users to buy with its simple display of product information."

"This website doesn't look messy and or busy."

This e-commerce site is aesthetically pleasing too and it uses a good colour scheme for easy readability. The colour scheme of black and white adopted by the site seems to go down well with participants' preference as it is able to emphasise focus on the products being sold on the website. The participants also said that the site had good quality and high definition images to display all the products. Participants' comments in support of this are as below:

"This site looks nice and has a modern look."

"The photos of the products look appealing and interesting. They are very clear and sharp."

"The images used within this site is very nice and lovely, and high quality too."

The participants also provided some suggestions which include the need for integration with customers' e-mail. One participant suggested that "integrating e-mail will help customers get vouchers." The participants also felt the need for updated status of their purchase and said they needed "latest information about products and events" to enhance their shopping experience.

Another noteworthy suggestion given by the participants is the inclusion of certain key features in the e-commerce site. One of these features suggested by many female participants is the feature of sorting of products according to price (low to high or high to low), as price is always an important consideration for female shoppers and are more deal-driven than males (Chea, 2011; Crobox, 2019). As contended by one of them, "this is to ease the users while navigating through the site." As confirmed by the findings by Rao et al. (2018), ease of use and convenience play a significant role in attracting online female customers.

A few participants went a step further by suggesting filtering of products. This is important to enable custormers to differentiate and distinguish different types of products. The main types of filters proposed were categories of brands, and colour. 
Finally, all the female participants said they would appreciate more varieties and categories of scarves and accessories to be included because women motivation for purchase is largely driven by style and fashion innovation (Chea, 2011).

\section{CONCLUSION AND RECOMMENDATION}

This research was carried out with the purpose of designing and developing a Shariah-compliant e-commerce fashion prototype called AZALEA. This website has been designed and developed based on Fogg's Persuasive Technology principles, using the principle of suggestion, principle of similarity and principle of trustworthiness that help persuade consumers to visit and eventually purchase products from this site. User Experience Testing was conducted to evaluate the screen layout, features and functionality. The findings of the study indicate that the information provided is useful and the website is well-designed. In addition, the suggested size and clothes based on users' body measurement is helpful in choosing suitable apparel based on body shape. Therefore, it can be concluded that this Shariah-compliant e-commerce fashion site is interesting, useful and user friendly.

There are several implications that can be further drawn from the study. Firstly, this Shariahcompliant fashion website is able to offer suggestions on suitable types of apparel for potential customers, based on their body shape. The findings showed that most users find the suggestion function to be very helpful. Users also concur that this feature is very useful in helping them choose a suitable product. In addition, majority of users agree that the website's ability in suggesting clothes based on body measurement is very convenient. This is because users do not have to measure their body and decide what size they should choose whenever they want to purchase any product. This feature should thus become an important add-on to other existing ecommerce site developers that focus on Shariah-compliant apparel, as it is able to take the sales and revenue of these sites to a greater level. As a Shariah-compliant e-commerce site, it also encourages more Muslim women to purchase and wear Shariah-compliant clothes, since all the products sold here are Shariah-compliant and strictly adhere to the commands of the Holy Qur'an and Hadith. Finally, this research has contributed to the existing literature in support of Persuasive Technology principles, where three principles were adopted in designing this website to persuade consumers to visit and purchase products from this site.

Besides, the suggested clothes and sizes on this e-commerce site are limited to an authorised user only. If an authorised user is buying for others, they do not get the suggestion on suitable products and size. They need to edit their body measurement or register a new account to get these suggestions.

The finding of this study has shed light on several leads for future research. This study could be extended by integrating other Persuasive Technology Principles such as principle of reduction and principle of self-monitoring that could increase the effectiveness of the e-commerce site. The study can also be replicated on a larger number of respondents as the present study was carried out on a smaller group. In terms of the e-commerce site, it could be improved by integrating other modules or functions, for example integration with customer's e-mail address. Integrating e-mail will help customers get vouchers, updated status of their purchase and obtain the latest information about products and events. Other features such as sorting and filtering of products 
should also be added to improve the website. As this study focused on user experience and usability aspects, payment module and notification of purchase status were not included. In further improving the site, payment module could be added to this site so that user experience on this module could be further probed, and the prototype can be evaluated on a comprehensive set of criteria.

The results and findings form the user experience together with the recommendations and suggestions from the participants could be used in enhancing and further improvising the ecommerce site. Refinement and improvements of the site could be made based on these suggestions. Further, another UX Testing session is proposed to evaluate the improvised version of this e-commerce site, which would benefit e-commerce developers and businesses that focus on this niche market today.

\section{REFERENCES}

Alserhan, B. A. (2010). Islamic brand: A conceptualization. Journal of Brand Management, 18(1), 34-49.

Cham, T. H., Ng, C. K. Y., Lim, Y. M., \& Cheng, B. L. (2018). Factors influencing clothing interest and purchase intention: A study of Generation Y consumers in Malaysia. The International Review of Retail Distribution and Consumer Research, 28(2),174-189. doi: 10.1080/09593969.2017.1397045

Chea, P. (2011). Gender differences in the fashion consumption and store characteristics in Swedish clothing stores. [Master's thesis, University of Borås]. Digitala Vetenskapliga Arkivet. http://www.diva-portal.org/smash/get/diva2:1312550/FULLTEXT01.pdf.

Crobox (2019). Men vs. women: How they shop. https://blog.crobox.com/article/men-womenshopping-differences

Fatema, M., Bhuiyan, F. A., \& Bhuiyan, M. A. (2013). Shari'a compliance in building identified Islamic brands. Islamic Management and Business, 5(11), 10-16. https://iiste.org/Journals/index.php/EJBM/article/view/5419/6223

Fogg, B. J. (2003). Using computers to change what we think and do. San Francisco, California: Morgan Kaufmann Publishers Inc.

Garrett, J. J. (2010). The elements of user experience: User-centered design for the web and beyond. Berkeley, California: Pearson Education.

Hervé, C., \& Mullet, E. (2009). Age and factors influencing consumer behaviour. International Journal of Consumer Studies, 33(3), 302-308.

Jan, M. T., Abdullah, K., \& Momen, A. (2015). Factors influencing the adoption of social networking sites: Malaysian Muslim users' perspective. Journal of Economics, Business and Management, 3(2), 267-270. https://10.7763/JOEBM.2015.V3.192

Jumani, Z. A., \& Siddiqui, K. (2012). Bases of Islamic branding in Pakistan: Perceptions or believes. Interdisciplinary Journal of Contemporary Research in Business, 3(9), 840847. https://journal-archieves14.webs.com/840-847.pdf

Khan, A. G. (2016). Electronic commerce: A study on benefits and challenges in an emerging economy. Global Journal of Management and Business Research, 16(1), 18-22. https://globaljournals.org/GJMBR_Volume16/3-Electronic-Commerce-A-Study.pdf

Kotler, P., \& Keller, K. L. (2012). A framework for marketing management $\left(5^{\text {th }}\right.$ ed.). New Hampshire: Pearson 
Lim, A. (2020). 3 Key takeaways on Malaysia's modest fashion ecommerce trends. https://janio.asia/articles/3-key-takeaways-on-malaysias-modest-fashion-ecommercetrends/

Mustafa@Busu, Z., Tasir, S. F., \& Mat Jusoh, N. A. (2018). The concept of aurah: Islamic dressing code and personal grooming according to Fiqh Law. e-Academia Journal, 7(2), 10-19. https://doi.org/10.24191/e-aj.v7i2.4682

Nemat, R. (2011). Taking a look at different types of e-commerce. World Applied Programming, 1(2), 100-104.

Organisation of Economic Co-operation Development. (OECD) (2020). COVID-19 and the retail sector: Impact and policy responses, OECD policy responses to Coronavirus (COVID19). http://www.oecd.org/coronavirus/policy-responses/covid-19-and-the-retail-sectorimpact-and-policy-responses-371d7599/

Omar, C. M. Z., \& Anas T. (2014). E-commerce in Malaysia: Development, Implementation and Challenge. International Review of Management and Business Research, 3(1), 291-298.

Ozge-Ozgen., \& Kurt, S. D. (2013). Purchasing behavior of Islamic brands: An experimental research. Paper presented at the $42^{\text {nd }}$ EMAC Annual Conference, Istanbul. https://www.scribd.com/document/337937472/2-Purchasing-Behavior-of-IslamicBrands-An-Experimental-Research-pdf

Rao, M. B., Hymavath, C. L., B. B., \& Rao, M. M. (2018). Factors affecting female consumer's online buying behaviour. Academy of Marketing Studies Journal, 22(2). https://www.abacademies.org/articles/factors-affecting-female-consumers-onlinebuying-behavior-7296.html

Ryu, G. \& Han, J. K. (2009). Word-of-mouth transmission in settings with multiple opinions: The impact of other opinions on WOM likelihood and valence. Journal of Consumer Psychology, 19(3), 403-415. https://doi.org/10.1016/j.jcps.2009.04.003

Salvá, A. (2017, May 17). Islamic fashion on the rise in Malaysia. The Diplomat. https://thediplomat.com/2017/05/islamic-fashion-on-the-rise-in-malaysia/

Six, J. M., \& Macefield, R. (2016). How to determine the right number of participants for usability studies. San Francisco (CA): UXmatters.

Smith, K. T. (2011). Consumer perceptions regarding e-commerce and related risks. https://www.westga.edu/ bquest/2011/ecommerce11.pdf

Swinker, M. E., \& Hines, J. D. (2006). Understanding consumers' perception of clothing quality: A multidimensional approach. International Journal Consumer Studies, 30(2), 218-223. https://doi.org/10.1111/j.1470-6431.2005.00478.x

Tajuddin, R. M., Tan, H. S., \& Karpova, E. E. (2010). Understanding apparel preferences in the multi-ethnic Malaysian market. Proceedings of the 67th Annual Conference of the International Textile and Apparel Association, 2010, 1-2. https://lib.dr.iastate.edu/aeshm_conf/42

Temporal, P. (2011). Islamic branding and marketing - Creating a global Islamic business. Singapore: John Wiley \& Sons (Asia) Pte. Ltd.

Tran, L. T. T. (2021). Managing the effectiveness of e-commerce platforms in a pandemic. Journal of Retailing and Consumer Services, 58, 102287. https://doi.org/10.1016/j.jretconser.2020.102287

Wilson, A. J., \& Liu, J. (2011). The challenges of Islamic branding: Navigating emotions and $\begin{array}{llll}\text { halal. Journal of } \quad \text { Islamic } & \text { Marketing, } & \text { 2(1), }\end{array}$ https://doi.org/10.1108/17590831111115222 